\title{
Pesquisa de Percepções de Estudantes do Ensino Médio sobre os Desafios Ambientais
}

\section{A Survey of High School Students' Perceptions about Environmental Challenges}

\author{
iD Cristine Santos de Souza da Silva ${ }^{1}$ \\ Tania Renata Prochnow ${ }^{1}$ \\ Giuseppe Pellegrini² \\ iD Nelio Bizzo ${ }^{3}$ \\ 1Universidade Luterana do Brasil (ULBRA), Canoas, RS, Brasil. Autora correspondente: cristine.silva@ulbra.br
2Università degli Studi di Trento, Trento, Italia.
${ }^{3}$ Universidade Federal de São Paulo (UNIFESP), Departamento de Ciências Exatas e da Terra, Diadema, SP, Brasil.
}

Resumo: Este estudo apresenta os resultados de uma investigação que teve por objetivo conhecer as opiniões de estudantes do Ensino Médio acerca dos desafios ambientais atuais, a fim de discutir o papel do ensino de ciências na formação de sua consciência ambiental. A pesquisa, que envolveu estudantes do ensino médio de escolas públicas e particulares da cidade de Canoas, Rio Grande do Sul, foi realizada por meio da aplicação de um questionário e os dados obtidos foram analisados em relação ao sexo e ao tipo de escola dos respondentes, por meio de ferramentas estatísticas. Os resultados demonstram que os jovens se preocupam com os problemas do ambiente e acreditam que a ciência é capaz de solucionar alguns deles, porém não demonstram otimismo em relação ao futuro do planeta. Diante disso, reforça-se a necessidade de que as problemáticas relacionadas aos desafios ambientais sejam contextualizadas no ensino de ciências, a fim de que habilidades reflexivas em relação ao tema possam ser incentivadas.

Palavras-chave: Educação ambiental; Ensino médio; Sustentabilidade; Consciência ambiental; CTSA.

Abstract: This study presents the results of a survey aimed at assessing high school students' opinions about current environmental challenges in order to discuss the role of science education in the development of students' environmental awareness. The survey, which involved high school students from public and private schools of Canoas, Rio Grande do Sul, was carried out with the administration of a questionnaire. The data were analyzed in relation to the gender and the type of school of the respondents, utilizing statistical tools. The results show that students care about the problems of the environment and believe that science can solve some of them, but they do not show optimism about the future of the planet. Therefore, results reinforce the need for contextualization of problems related to environmental challenges in science lessons, aiming at further developing students' reflexive skills.

Keywords: Environmental education; High school; Sustainability; Environmental awareness; STSE.

Recebido em: 24/04/2019

Aprovado em: 24/10/2019 


\section{Introdução}

O ensino de ciências desempenha um papel social de extrema relevância para o cidadão comum, uma vez que prepara os jovens para viver, conviver, interagir e entender o mundo em que estão inseridos. As alterações ambientais atuais, e suas consequências, são motivo de preocupação para todas as sociedades. Por isso, a discussão dessas questões em sala de aula possibilita aos estudantes um outro olhar sobre a relevância do conhecimento científico, uma vez que os impactos ambientais estão associados, de forma direta ou indireta, aos conteúdos ensinados nas aulas de ciências.

Quando se alia a temática ambiental aos conteúdos científicos, uma compreensão mais complexa acerca do planeta e da sustentabilidade planetária é favorecida. Apesar disso, ainda é grande o desafio de educar para a promoção da conscientização socioambiental, pois trata-se de uma tarefa que se relaciona diretamente à percepção e à formação de um pensamento ecológico complexo, onde é necessário que o indivíduo se entenda participante, pertencente e corresponsável por tudo o que ocorre no mundo que o cerca (FERREIRA, 2011; JACOBI, 2005).

A formação da consciência ambiental depende da educação, que possibilita ampliar conhecimentos, mudar comportamentos, ressignificar valores, questionar posturas e aperfeiçoar habilidades, além de priorizar a integração e a harmonia dos indivíduos com o meio ambiente. Neste sentido, admite-se que a importância da educação ambiental para a inserção do discurso sobre sustentabilidade no contexto educacional está relacionada tanto ao estabelecimento de regras de formação de conduta ético-indivíduo-social, quanto ao despertar nos estudantes os interesses pelo componente ambiental (ARAÚJO; BIZZO, 2005; GADOTTI, 2009).

Apesar dessas premissas, segundo alguns autores, a educação ambiental no âmbito escolar foi implementada de forma isolada e distante do cotidiano, o que acabou ocasionando sua pouca eficiência na transformação do cidadão ambientalmente consciente. Algumas referências atribuem a isso, o fato das questões ambientais serem tratadas no ensino de ciências dentro de um viés reducionista, que considera os problemas ambientais como uma crise meramente ecológica, desprezando as dimensões políticas, éticas e culturais (BASTOS; NUNES; FREITAS, 2014; BOURSCHEID; FARIAS, 2014; MALAGODI, 2013).

Nessa perspectiva, Gadotti (2008) argumenta que o ensino de ciências deve ter seu enfoque voltado à sustentabilidade, pois assim, seriam enfatizados no processo de ensino a aprendizagem de atitudes, perspectivas e valores que orientam os seres humanos a viverem de forma integrada ao ambiente, ao mesmo tempo em que os estimulam a se tornarem responsáveis pela promoção do desenvolvimento sustentável no meio onde vivem.

A aprendizagem é um processo ativo e engajado com a experiência, segundo o que argumenta Dillon (2003). É importante considerar o que as pessoas fazem para entender o mundo e por isso, as experiências pessoais devem fazer parte de ensino, pois assim é possível envolver no processo da aprendizagem um conjunto de habilidades, conhecimentos ou compreensões, e um aprofundamento de valores ou da capacidade de reflexão sobre o ambiente que cerca os indivíduos. O autor ainda afirma que a educação ambiental nesse sentido, torna a aprendizagem eficaz, e por consequência, leva a mudanças, desenvolvimento e um desejo de aprender ainda mais. 
A ética da sustentabilidade propõe a interligação de processos ecológicos, sociais, econômicos, culturais e tecnológicos a fim de se obter uma sociedade sustentável. Por esse motivo, é possível inserir o discurso sobre a sustentabilidade no ensino de ciências mediante a compreensão de que a dimensão ambiental vai além dos conceitos ecológicos. Essa compreensão também é favorecida pela interdisciplinaridade, que no âmbito do ensino, atua como facilitadora da aquisição do conhecimento e do desenvolvimento de valores que não podem ser reduzidos, nem abordados exclusivamente através da problemática ambiental, mas sim, devem estar ancorados nas transformações sociais que o momento atual exige (ARAÚJO; BIZZO, 2005; CARVALHO; PILAU SOBRINHO; RAMIRES, 2015; CRUZ; DINIZ, 2015).

Para Wals et al. (2004) o ensino de ciências serve para engajar as pessoas naqueles que são comumente referidos como 'desafios de sustentabilidade', principalmente no que se refere às questões mais urgentes, como por exemplo, as alterações climáticas, a produção de alimentos, a desnutrição, o consumismo e perda de biodiversidade. Os autores alertam ainda sobre a necessidade de se buscar, por meio de estratégias de ensino, o resgate à identidade ambiental local que determina nossas relações com o planeta, isso porque a globalização e os avanços tecnológicos dos últimos tempos promoveram uma certa desconexão do homem com o ambiente, afetando principalmente sua noção de pertencimento à natureza.

Diante dessas considerações, esse artigo apresenta os resultados de uma investigação realizada com estudantes do Ensino Médio de escolas particulares e públicas, localizadas na cidade de Canoas, RS, tendo como objetivo conhecer as opiniões dos jovens acerca dos desafios ambientais atuais a fim de discutir sobre o papel do ensino de ciências na formação da consciência ambiental dos estudantes.

\section{A Perspectiva Socioambiental no Ensino de Ciências}

Dentre as diversas abordagens dadas ao ensino de ciências na atualidade, a perspectiva socioambiental aliada às temáticas científicas encontra-se fortemente ancorada nos pressupostos do enfoque Ciência, Tecnologia, Sociedade e Ambiente (CTSA). O enfoque metodológico CTSA é oriundo do movimento Ciência, Tecnologia e Sociedade (CTS), que surgiu na década de 1980 com o objetivo de dar relevância ao ensino de ciências, a fim de implementar a compreensão científica e, ao mesmo tempo, discutir de forma mais ampla as questões e implicações do mundo tecnológico (AIKENHEAD, 2005; COURVILLE, 2009; KOLST $\varnothing, 2006$ ). Com o passar do tempo, observou-se que o movimento CTS favorecia a aproximação das questões ambientais ao ensino de ciências, aumentando assim sua abrangência e perspectiva, acrescentando então o ambiente a sua sigla, mudando de CTS para CTSA (BOURSCHEID; FARIAS, 2014; CACHAPUZ et al., 2005).

Para Aguiar-Santos, Vilches e Brito (2016), mais do que a ênfase dada aos temas ambientais, a abordagem CTSA promove a intensificação de estudos e ações em busca da sustentabilidade, já que nas últimas décadas ficou evidente o agravamento das questões socioambientais oriundas das atividades humanas. O ensino de ciências nessa perspectiva tem como função promover aos estudantes a aquisição do conhecimento necessário ao desenvolvimento da consciência crítica, que não se satisfaz com as aparências, mas busca investigar, aprofundar e analisar o problema, tendo como pressuposto a visão integrada ciência e da tecnologia e dos seus impactos na sociedade e no ambiente. 
A abordagem CTSA possibilita que os alunos não fiquem com uma ideia engessada da ciência, pois enfatiza questões cotidianas e que fazem parte da realidade dos educandos, os despertem para o exercício da uma cidadania responsável e consciente, bem como propiciem o desenvolvimento de competências que os tornem capazes de utilizar os conhecimentos adquiridos na escola em seus contextos de vida (FERNANDES; PIRES; VILLAMAÑÁN, 2013).

A expressiva dependência tecnológica da sociedade atual, onde os avanços científicos e tecnológicos são quase diários, torna o ensino de ciências com orientação CTSA uma necessidade. Contudo, para sua efetividade, é importante que sejam explorados tópicos científicos em função da sua utilidade social, ou seja, que possibilitem ao aluno desenvolver uma atitude crítica, fundamentada nos pressupostos da ciência, porém, considerando problemas socioambientais a partir de exemplos de tecnologias recentes, aplicadas na vivência do seu dia-a-dia (FERNANDES, 2011; FERNANDES; PIRES, 2012).

O principal objetivo da perspectiva CTSA é educar para sustentabilidade. Sendo assim, torna-se imperativo que no currículo do ensino de ciências sejam enfatizados conteúdos que estejam interconectados com a dimensão holística que o conceito de ambiente possui, ou seja, trabalhar com os estudantes temáticas socioambientais associadas a considerações éticas, tecnológicas, culturais e ecológicas, uma vez que o conceito de sustentabilidade está associado a forma como a sociedade pensa e age (BARRAZA; CASTAÑO, 2012). O uso dessa abordagem no âmbito do ensino de ciências tem muito a contribuir para a aprendizagem significativa, pois a investigação e explanação acerca de temas ambientais que partem de situações próximas à realidade do aluno, pode levá-lo a interessar-se pela ciência, uma vez, que por meio da contextualização dos pressupostos teóricos científicos ele irá sentir-se inserido de forma ativa e não simplesmente como mero receptor de informações (VILCHES; GIL-PÉREZ; PRAIA, 2011).

Segundo Ribeiro e Genovese (2015), a contextualização na perspectiva CTSA de ensino está baseada na pesquisa e na problematização de temas cotidianos. Sua intensão é criar mecanismos para promover uma compreensão atual e mais ampla da natureza, da ciência e da tecnologia, e do seu papel na sociedade atual. Em uma análise mais aprofundada, Torres Merchán (2011) afirma que essa contextualização abarca pressupostos da teoria freiriana, uma vez que objetiva a formação de sujeitos críticos em uma perspectiva educacional que busca justiça e igualdade social.

Contudo, embora a contextualização possa parecer algo simples em uma primeira análise, sua implementação demanda o rompimento de diversos obstáculos metodológicos. O par metodologia-conteúdo não pode ser deixado de lado, estando aí um grande desafio para os professores, uma vez que a abordagem CTSA, "[...] não esvazia a escola dos saberes teóricos, conceitos e modelos, nem os dilui em generalidades, ao contrário, exige maior profundidade dos temas escolhidos para estudo". (RICARDO, 2008, p. 7).

Sobre isso, Ribeiro e Genovese (2015) orientam que é necessário que o ensino de ciências estabeleça relações entre os saberes pessoais dos alunos e os conteúdos curriculares. Desse modo, os alunos poderão perceber e compreender aspectos científicos, tecnológicos e socioambientais do seu cotidiano. Essa consideração conjunta de distintos saberes, tanto provenientes do currículo quanto provenientes de sua vivência, demonstra ser proveitosa para solução de problemas reais e para compreender muitos fenômenos do cotidiano.

Sendo assim, é importante entender que os saberes provenientes do currículo devem igualmente ser considerados, a fim de que, por meio dessa perspectiva, os saberes estritamente científicos sejam ampliados, passando a interagir com os saberes sociais, 
éticos e morais, ambientais, entre outros. É preciso que seja levado em conta também, que existem diferenças epistemológicas e ontológicas entre o raciocínio cotidiano e o raciocínio científico, por esse motivo, as ferramentas culturais da ciência precisam ser apresentadas aos alunos, cabendo ao professor o papel de elucidar, construir e, se for preciso, descontruir aqueles conhecimentos do senso comum que não condizem os conhecimentos científicos (BAPTISTA, 2010; DRIVER et al., 1999).

\section{Metodologia da Pesquisa}

O estudo apresentado nesse artigo foi realizado com jovens, estudantes do Ensino Médio, de escolas particulares e públicas localizadas no município de Canoas, na região metropolitana de Porto Alegre, capital do estado do Rio Grande do Sul, RS. Participaram do estudo 19 das 26 escolas de Ensino Médio do município. Em cada escola selecionou-se aleatoriamente uma turma de cada ano do Ensino Médio $\left(1^{\circ}, 2^{\circ}\right.$ e $3^{\circ}$ anos), do turno diurno (matutino ou vespertino).

A pesquisa realizada está vinculada ao Projeto Saberes do Alunado na Perspectiva Internacional: Evolução, Natureza e Sociedade (SAPIENS) que deriva da aplicação do Projeto internacional ROSE (The Relevance of Science Education) no Brasil. De acordo com Sjøberg e Schreiner (2010), um dos objetivos do ROSE é reunir e analisar informações sobre a relevância do ensino de ciências e sobre os vários fatores que influenciam os alunos em suas atitudes e suas motivações para aprender ciências. Por esse motivo, o instrumento adotado para coleta de dados foi o questionário 'Barômetro: os jovens e a ciência', oriundo da redução dos itens do questionário ROSE, contudo preservando, por meio de análises estatísticas, sua consistência interna (BIZZO; PELLEGRINI, 2015; PINAFO, 2016). O questionário Barômetro é composto por 120 questões, distribuídas em 9 seções nomeadas de A até I, cada qual abordando uma temática específica. A fim de atender aos objetivos desse artigo, uma vez que ele apresenta um recorte da tese de doutorado de Silva (2019), apenas os resultados da Seção C: Eu e os desafios ambientais serão apresentados e discutidos.

A Seção C é formada por 14 afirmações que investigam as opiniões dos respondentes em relação aos desafios ambientais. As opções de resposta variavam em relação ao nível de concordância com a afirmação em questão, em uma escala de 4 pontos, sendo: (4) concordo totalmente; (3) concordo; (2) discordo; $\mathrm{e}$, (1) discordo totalmente. Os resultados foram analisados em relação às respostas por sexo e por tipo de escola. Foram admitidas as médias gerais encontradas em cada afirmativa, considerado o índice de 2,5 como um resultado neutro, ou seja, índices maiores revelando concordância e índices menores revelando discordância.

Os resultados das variáveis nominais foram expressos através de análises de frequência e os resultados das variáveis continuas através de média \pm desvio padrão. Também foram aplicados testes estatísticos com auxílio do software SPSS 21.0, onde se adotou como nível de significância 95\%. Além disso, as afirmações foram agrupadas em categorias, de acordo com a postura que a concordância com elas representa, conforme apresenta o quadro 1: 
Quadro 1 - Categorias que representam as posturas ambientais

\begin{tabular}{|l|l|l|}
\hline \multicolumn{1}{|c|}{ Categoria } & \multicolumn{1}{|c|}{ Descrição } & \multicolumn{1}{c|}{ Questões } \\
\hline Ecocêntrica & Postura proativa relacionada às questões ambientais & C29, C31, C33, C35, C39 \\
\hline Eco-apática & $\begin{array}{l}\text { Postura indiferente ou passivas em relação ao ambiente e às } \\
\text { problemáticas envolvidas }\end{array}$ & C28, C34, C37, C38, C40 \\
\hline Ecopessimista & $\begin{array}{l}\text { Postura negativas e pessimista em relação ao ambiente e ao } \\
\text { futuro do planeta }\end{array}$ & C41 \\
\hline Eco-otimista & $\begin{array}{l}\text { Postura otimista em relação ao futuro do planeta e aos im- } \\
\text { pactos das atividades humanas }\end{array}$ & C30, C32 \\
\hline Eco-individualista & $\begin{array}{l}\text { Postura antropocêntrica, priorizando a vida humana acima } \\
\text { da dos outros seres vivos }\end{array}$ & C36 \\
\hline
\end{tabular}

Fonte: adaptado de Gouw (2013).

\section{Resultados e Discussão}

Participaram da pesquisa um total de 1.331 jovens, com idades entre 14 e 18 anos. (média $=\mathrm{X}$ e $\mathrm{DP}=\mathrm{Y}$ ). A distribuição por sexo na amostra foi igualitária, contando com a participação de 666 meninas e 665 meninos. No total, a participação de estudantes de escolas públicas foi maior do que particulares, tendo ao todo 1151 (86,5\%) jovens da escola pública e 180 (13,5\%) da escola particular, todos frequentando o período diurno (matutino/ vespertino). Os resultados encontrados na análise geral dos dados relativos às questões da Seção C estão apresentados no quadro 2.

Quadro 2 - Médias gerais da Seção C ('Eu e os desafios ambientais')

\begin{tabular}{|c|c|c|}
\hline Questões & Média & $\begin{array}{l}\text { Desvio } \\
\text { padrão }\end{array}$ \\
\hline C1 - A ciência e a tecnologia podem resolver problemas do ambiente & 3,1 & 0,7 \\
\hline C2 - Eu pessoalmente posso influenciar o que acontece ao ambiente & 3,1 & 0,7 \\
\hline C3 - Ainda podemos encontrar soluções para os problemas do ambiente & 3,3 & 0,6 \\
\hline C4 - As pessoas deveriam interessar-se mais pela proteção do ambiente & 3,5 & 0,6 \\
\hline C5 - Eu estou otimista quanto ao futuro do planeta & 2,2 & 0,8 \\
\hline C6 - O mundo natural é sagrado e devemos deixa-lo em paz & 2,9 & 0,8 \\
\hline C7 - As pessoas se preocupam demais com os problemas ambientais & 1,7 & 0,8 \\
\hline C8 - Penso que cada um de nós pode dar uma contribuição significativa para proteção do ambiente & 3,4 & 0,7 \\
\hline C9 - É correto usar animais pra experiências médicas se assim for possível salvar vidas humanas & 2,1 & 1,0 \\
\hline C10 - Os problemas do ambiente devem ser deixados aos especialistas & 2,0 & 0,8 \\
\hline C11 - É responsabilidade dos países ricos resolverem os problemas ambientais do mundo & 1,9 & 0,8 \\
\hline C12 - Os animais devem ter o mesmo direito à vida que as pessoas & 3,2 & 0,8 \\
\hline C13 - As ameaças ao ambiente não são da minha conta & 1,5 & 0,7 \\
\hline C14 - Os problemas do ambiente são exagerados pela mídia & 1,8 & 0,8 \\
\hline
\end{tabular}

Fonte: elaborado pelos autores a partir dos dados da pesquisa.

A análise dos dados revelou que, de forma geral, os jovens demonstram grande preocupação com o ambiente, inclusive trazendo para si a responsabilidade pela proteção ambiental. Essa constatação é revela pelos altos índices de concordância apresentados nas questões C4, C8 e C2, e pelos índices de discordância em relação às questões C10, C11 e C13. Já ao se comparar os índices das questões C12 e C9 nota-se que os jovens demonstram ser sensíveis em relação à proteção animal. 
Da mesma forma, observou-se um significativo grau de confiança de que a ciência é capaz de solucionar alguns problemas ambientais (questões C1 e C3), apesar de não demonstrarem otimismo em relação ao futuro do planeta (questão C5).

Ao analisar os resultados considerando o sexo dos jovens, observou-se que as opiniões de meninos e meninas são estatisticamente semelhantes, apresentando índices discrepantes $(p<0,05)$ apenas em relação a questão $(12$, onde se observa maior concordância das meninas em relação à questão que se refere aos direitos dos animais. Os resultados da análise das questões por sexo dos respondentes estão apresentados no gráfico da Figura 1.

Figura 1 - Médias da Seção C ('Eu e os desafios ambientais') considerando o sexo dos respondentes

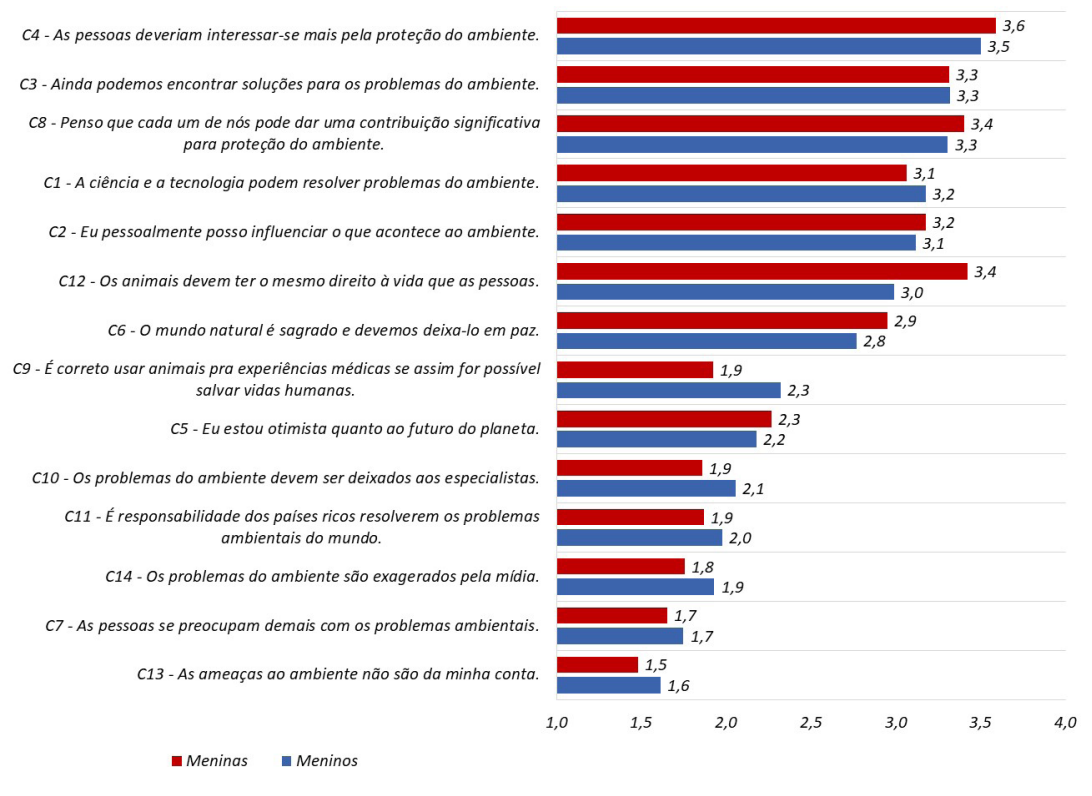

Fonte: elaborada pelos autores a partir dos dados da pesquisa.

Como se pode observar, os estudantes concordam (parte superior da figura 1, média acima de 2,5) com afirmações que enfatizam a responsabilidade de todos pelo ambiente. Ao mesmo tempo, discordam de afirmações que os desobrigam dos problemas ambientais (parte inferior da figura 1, média abaixo de 2,5). Esses resultados corroboram a afirmação presente em um estudo realizado pelo Instituto Akatu (2003, p. 9) que diz que é notório "[...] em qualquer quadrante do planeta, o crescimento entre os jovens de uma consciência ecológica, ligada à preservação da vida e das condições de coexistência da humanidade e a natureza".

Segundo Alves (2013), a postura preocupada dos jovens em relação aos desafios do ambiente foi, em parte, favorecida pela globalização e pelo acesso à informação, podendo ser por isso que a geração atual seja considerada a mais interessada nos assuntos ambientais, e portanto, mais consciente do impacto que suas atitudes exercem sobre os ecossistemas. Contudo, apesar disso, essa consciência não é colocada prática, pois apesar dos jovens demonstrarem pensar diferente dos seus pais, seguem suas mesmas atitudes degradantes, principalmente no que tange aos seus comportamentos consumistas. 
Ao se analisar os resultados por questão considerando o tipo de escola dos jovens, percebeu-se que há alguma diferença em relação às médias encontradas nos dois contextos. Pode-se perceber nesta análise que os jovens da escola particular são um pouco mais esclarecidos em relação às suas responsabilidades com as questões ambientais, como se pode observar no gráfico da Figura 2, nos resultados das questões C2, C10 e C13, principalmente.

Figura 2 - Médias da Seção C, considerando o tipo de escola frequentada pelos respondentes

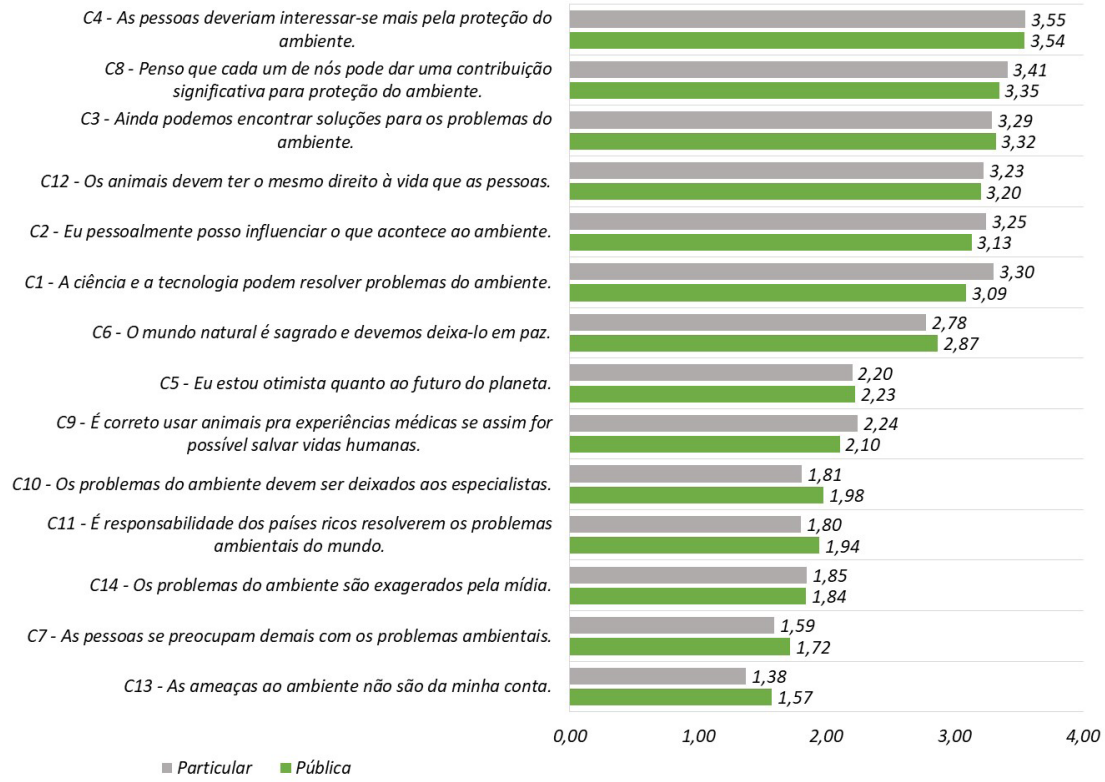

Fonte: elaborada pelos autores a partir dos dados da pesquisa.

Ao se analisar as posturas dos jovens considerando as categorias determinadas pela metodologia do trabalho, nota-se o predomínio das posturas Ecocêntrica e Eco-otimista, uma vez que apresentam médias superiores a 2,5. Sendo ainda possível observar, que as meninas apresentam médias superiores as dos meninos, no que tange à primeira categoria. Todavia, em relação à postura Eco-individualista, chama a atenção que a média dos meninos $(2,32)$ é bastante superior à das meninas $(1,92)$, sendo essa diferença corroborada estatisticamente ( $p<0,05)$. O gráfico da Figura 3 apresenta os resultados da análise das posturas dos jovens em relação às questões ambientais, agrupando-os por sexo.

Figura 3 - Posturas frente às questões ambientais considerando o sexo dos jovens

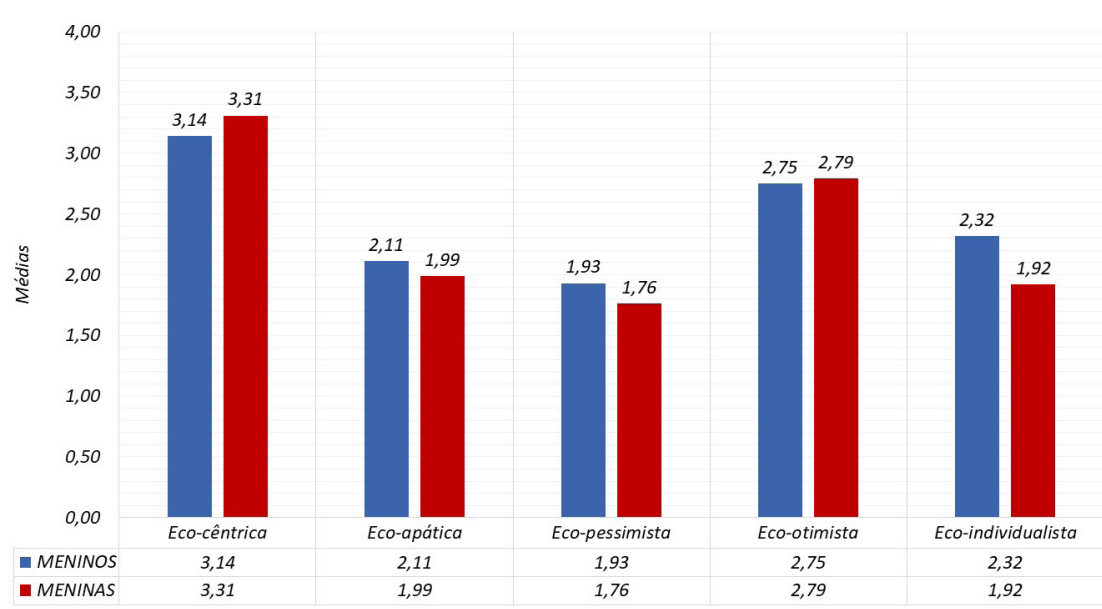

Fonte: elaborada pelos autores a partir dos dados da pesquisa. 
Semelhante ao encontrado nessa pesquisa foi observado nos resultados da pesquisa de Gouw (2013), que aplicou o questionário ROSE no contexto nacional. Em seu estudo, a pesquisadora verificou que as maiores médias também estavam associadas às posturas Ecocêntrica e Eco-otimista, notando-se, inclusive, o mesmo padrão apresentado nesse artigo, onde as médias das meninas superam as dos meninos na categoria Ecocêntrica.

Em relação ao contexto escolar, evidenciam-se posturas semelhantes dos jovens, independentemente do tipo de escola. À exceção disso, destaca-se apenas a postura Ecoindividualista onde percebe-se um índice superior atribuído aos jovens da escola particular, em relação ao índice dos jovens da escola pública, como demonstra o gráfico da Figura 4.

Figura 4 - Posturas dos jovens frente às questões ambientais

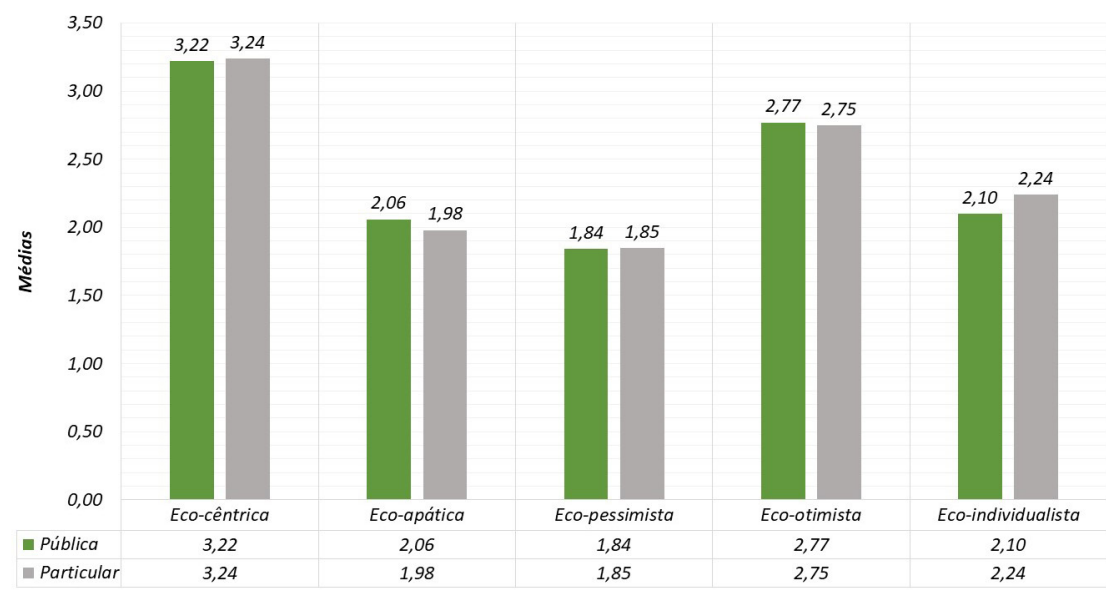

Fonte: elaborada pelos autores a partir dos dados da pesquisa.

Sobre esse resultado, Brandão, Brandão e Moura (2015) argumentam que estudantes de escolas particulares, via de regra, se encontram em uma condição privilegiada em relação aos de escolas públicas. Em contrapartida, o fato de apresentarem uma postura individualista em relação a natureza pode estar associado à adoção de um comportamento mais consumista.

A pesquisa de Utpadel (2007), que investigou comportamentos de consumo dos jovens, identificou um padrão semelhante ao encontrado nessa pesquisa, pois ao comparar comportamentos de consumo de estudantes de escolas públicas e particulares, notou que os alunos da escola particular se apresentaram mais consumistas que os alunos da escola pública, e explica que, para esses jovens, o ato de consumir está relacionado a imagem que esse grupo faz de si mesmo, onde não apenas a mídia exerce influência sobre esse comportamento, mas também, as próprias referências sociais e elitistas dos grupos de amigos que os cercam.

\section{O Papel do Ensino de Ciências na Formação da Consciência Ambiental}

Diante do resultado encontrado nessa pesquisa, cabe a reflexão acerca do papel que o ensino de ciências deve exercer na formação da consciência ambiental dos estudantes, bem como a sua contribuição para a mudança comportamental cada vez mais urgente no âmbito dos desafios ambientais da atualidade. É necessário atingir o aluno na sua emoção, de forma que por meio dessa sensibilização seja gerada a mudança de atitude que é necessária, e 
assim se possa tornar o ensino de ciências mais relevante, despertando a consciência crítica dos jovens para que eles considerem os pressupostos científicos nas suas atitudes e escolhas diárias.

Sobre isso, Santos e Mortimer (2009) sugerem que questões sociocientíficas sejam incentivadas por meio de debates e discussões em sala de aula, onde seja permitido aos alunos desenvolverem habilidades reflexivas e argumentativas. Os autores trazem uma abordagem pedagógica do ensino de ciências que envolvem cinco objetivos, a saber:

(1) relevância - encorajar os alunos a relacionar suas experiências escolares em ciências com problemas de seu cotidiano e desenvolver responsabilidade social; (2) motivação - despertar um maior interesse dos alunos pelo estudo de ciências; (3) comunicação e argumentação - ajudar os alunos a se expressar, ouvir e argumentar; (4) análise - ajudar os alunos a desenvolver raciocínio com maior exigência cognitiva;

(5) compreensão - auxiliar na aprendizagem de conceitos científicos e de aspectos relativos à natureza da ciência (RATCLIFFE, 1998 apud SANTOS; MORTIMER, 2009, p. 192).

Observa-se que, nesse enfoque, a contextualização é favorecida e a abordagem de assuntos relacionados a questões cotidianas acaba possibilitando que o conteúdo de ciências tenha uma maior aproximação à realidade vivenciada pelos jovens, favorecendo a desmistificação da inaplicabilidade do conhecimento científico. Porém, os mecanismos necessários à tomada de consciência acerca dos desafios ambientais são mais amplos do que somente a educação escolar.

O modelo consumista irresponsável está ancorado em diferentes correntes e, portanto, não basta apenas modificar a abordagem de ensino ou simplesmente colocar unicamente sobre o professor a responsabilidade de mudar esse sistema. Cachapuz et al. (2005, p. 179) defendem que a renovação do ensino de ciências é uma necessidade urgente. Sendo importante, para isso, que os professores atualizem-se por meio de workshops, cursos e seminários, entre outras modalidades de formação continuada, dialoguem e troquem experiências de forma a ampliar suas percepções acerca da situação planetária, podendo, assim, traçar estratégias pedagógicas que sejam capazes de "[...] provocar uma mudança em profundidade que afete de maneira durável os comportamentos" dos seus alunos.

Contudo, é também importante levar em consideração o contexto educacional como um todo, entendendo que o processo de renovação não depende apenas dos professores, mas sim de toda a sociedade que influencia e é influenciada pelos processos culturais que moldam e dão relevância, ou não, ao que está sendo ensinado (ou ao que se pretende ensinar) em sala de aula. Nesse sentido, cabe citar o que disse Krasilchik (1993) há mais de 25 anos atrás ao analisar os caminhos do ensino de ciências no Brasil, e que mesmo hoje parece ser bastante atual:

Reformas que desconsideram a necessidade de formar professores, com autonomia para planejar e competência para agir de acordo com suas convicções, estão fadadas ao fracasso. Perspectivas de sucesso baseiam-se em um processo coletivo que envolve, nessa reforma, não apenas a comunidade educacional, mas toda a sociedade que hoje, reiteradamente, cobra uma educação mais significativa e eficiente. (KRASILCHIK, 1993, p. 6). 
A preocupação dos jovens com o meio ambiente não se manifesta apenas dentro da escola, mas também na comunidade. Recentemente, uma jovem sueca, Greta Thumberg, envolveu milhares de jovens de todo o mundo para uma greve ambiental (FRIDAY FOR FUTURE, 2019) demonstrando como o comportamento pode ser alterado a partir de uma orientação crítica em relação às políticas ambientais. A repercussão de seu clamor foi muito grande em diversas partes do mundo, ao ponto de ser convidada para um pronunciamento na Organização das Nações Unidas em setembro de 2019, evidenciando a relevância das atitudes dos jovens frente aos desafios ambientais.

Segundo Santos e Costa (2017) a escola possui um papel imprescindível para a formação humana, porém, apesar da crescente preocupação com a atual situação do ambiente, ela acaba reproduzindo e disseminando as práticas que promovem a degradação ambiental. Todavia, não é da escola a culpa pelos processos que geram essa degradação, mas sim resultado do construto social vigente na cultura humana atual. Não se pode dizer que todos os problemas, ambientais ou sociais, poderão ser resolvidos totalmente na escola, mas é no seu ambiente que esses problemas poderão ser pensados e discutidos e, dessa forma, a sensibilidade necessária à promoção da mudança comportamental da sociedade poderá ser estimulada.

Sendo assim, é preciso que se entenda a escola como parte importante de um processo pedagógico, mas não único, uma vez que o desenvolvimento educacional com foco na ciência e nas problemáticas ambientais é um processo amplamente cultural, ou seja, envolve a família, os estudantes, os professores, as mídias e a sociedade em geral, pois todos estes são atores que formam a rede que influenciam as percepções ambientais dos jovens.

\section{Agradecimentos}

Esta pesquisa foi possível graças à colaboração de diversas agências de fomento e de pessoas. Agradecimentos são devidos a Svein Sjøberg, Cláudia Lisete Oliveira Groenwald, Ana Maria Santos Gouw, Graciela Oliveira, Luiz Caldeira Tolentino Neto e Daniel Morin Ocampo.

A montagem da base de dados contou com o apoio, mesmo que parcial, do Conselho Nacional de Desenvolvimento Científico e Tecnológico (CNPq, processos 476205/2013-1 e 308877/2015-2), Coordenação de Aperfeiçoamento de Pessoal de Ensino Superior (CAPES/ MEC-PAEP, processo 6726/2012-76), Fundação de Amparo à Pesquisa do Estado de São Paulo (FAPESP, processo 2016/05843-4), Pró-Reitoria de Pesquisa da Universidade de São Paulo (EDEVO/Darwin-USP), Faculdade de Educação da USP, PPGECIM-ULBRA/Canoas, e Observa Science in Society (Vicenza, Itália).

\section{Referências}

AGUIAR-SANTOS, D.; VILCHES, A.; BRITO, L. P. Importância concedida à CTSA e sustentabilidade em revistas de investigações científicas educacionais no Brasil e Espanha. Indagatio Didactica, Aveiro, v. 8, n. 1, p. 1809-1820, 2016.

AIKENHEAD, G. S. Research into STS science education. Educación Química, México, v. 16, n. 3, p. 384-397, 2005. DOI: https://doi.org/10.22201/fq.18708404e.2005.3.66101 
ALVES, N. B. A consciência ambiental dos jovens: uma pesquisa com estudantes de nível médio técnico e superior tecnológico. 2013. Dissertação (Mestrado em Administração) - Escola de Administração, Universidade Federal do Rio Grande do Sul, Porto Alegre, 2013.

ARAÚJO, M. I. O.; BIZZO, N. O discurso da sustentabilidade, educação educação ambiental e a formação de professores de biologia. Enseñanza de las Ciencias, Barcelona, p. 1-5, 2005. (Número extra).

BAPTISTA, G. C. S. Importância da demarcação de saberes no ensino de ciências para sociedades tradicionais. Ciência \& Educação, Bauru, v. 16, n. 3, p. 679-694, 2010. DOI: https://doi.org/10.1590/ S1516-73132010000300012

BARRAZA, L.; CASTAÑO, C. ¿Puede la enseñanza de la ciencia ayudar a construir uma sociedad sostenible? Profesorado, Granada, v. 16, n. 2, p. 45-58, 2012. Disponível em: http://hdl.handle. net/10481/23020. Acesso em: 8 jun. 2020.

BASTOS, A. T.; NUNES, J. B. C.; FREITAS, A. A. F. Educação para a sustentabilidade em cursos de graduação a distância: análise de uma IES pública do nordeste do Brasil. Revista Eletrônica de Educação, São Carlos, v. 8, n. 3, p. 147-163, 2014. DOI: https://doi.org/10.14244/198271991000

BIZZO, N.; PELLEGRINI, G. Os jovens e a ciência. Curitiba: CRV, 2015.

BOURSCHEID, J. L. W.; FARIAS, M. E. A convergência da educação ambiental, sustentabilidade, ciência, tecnologia e sociedade (CTS) e ambiente (CTSA) no ensino de ciências. Revista Thema, Pelotas, v. 11, n. 1, p. 24-36, 2014. DOI: https://doi.org/10.15536/thema.11.2014.24-36.183

BRANDÃO, I. J.; BRANDÃO, J. F. C.; MOURA, C. M. A. Consumismo como forma de impacto ambiental: um comparativo entre jovens de escola pública e particular de Manhuaçu- MG. In: SEMINÁRIO CIENTÍFICO DA FACIG, 1., 2015, Manhuaçu. Anais [...]. 2015. Manhuaçu: UNIFACIG, 2015. p. 1-8.

CACHAPUZ, A.; GIL-PEREZ; D.; CARVALHO, A. M. P.; PRAIA, J.; VILCHES, A. A necessária renovação do ensino das ciências. São Paulo: Cortez, 2005.

CARVALHO, S. A.; PILAU SOBRINHO, L. L.; RAMIRES, C. C. O paradigma de desenvolvimento sustentável e de sustentabilidade na modernidade: utopia ou realidade. Revista FSA, Teresina, v. 12, n. 1, p. 61-78, 2015.

COURVILLE, K. Science, technology, and society: a perspective on the enhancement of science education. In: LOUISIANA ASSOCIATION OF MATHEMATICS TEACHERS / LOUISIANA SCIENCE TEACHER ASSOCIATION JOINT CONFERENCE, 2009, Shreveport. Proceedings [...].Shreveport: Louisiana State University, 2009. p. 1-19. Disponível em: https://files.eric.ed.gov/fulltext/ED507405. pdf. Acesso em: 8 jun. 2020.

CRUZ, L. G.; DINIZ, R. E. S. A educação ambiental no contexto escolar na década da educação das Nações Unidas para o desenvolvimento sustentável (2005-2014). In: ENCONTRO NACIONAL DE PESQUISA EM EDUCAÇÃO EM CIÊNCIAS, 10., 2015, Águas de Lindóia. Anais [...]. Disponível em: https://tinyurl.com/ycwq6ks4. Acesso em: 8 jun. 2020.

DILLON, J. On learners and learning in environmental education: missing theories, ignored communities. Environmental Education Research, Abingdon, v. 9, n. 2, p. 215-226, 2003. DOI: https:// doi.org/10.1080/13504620303480

DRIVER, R.; ASOKO, H.; MORTIMER, E.; SCOTT, P. Construindo conhecimento científico na sala de aula. Química Nova na Escola, São Paulo, n. 9, p. 31-40, 1999. 
FERNANDES, I. M. B. A perspectiva CTSA nos manuais escolares de ciências da natureza do $2^{\circ}$ CEB. 2011. 132 f. Dissertação (Mestrado em Ensino de Ciências) - Instituto Politécnico de Bragança, Escola Superior de Educação, Bragança, 2011.

FERNANDES, I. M. B.; PIRES, D. M. Integração CTSA em manuais escolares de ciências da natureza do $5^{\circ}$ ano de escolaridade. In: SEMINARIO IBEROAMERICANO CTS EN LA ENSEÑANZA DE LAS CIENCIAS, 3., 2012, Madrid. Actas [...]. Madrid: OEl, 2012. p. 52-58.

FERNANDES, I.; PIRES, D.; VILLAMAÑÁN, R. M. Educação em ciências com orientação CTSA: construção de um instrumento de análise das orientações curriculares. In: CONGRESO INTERNACIONAL SOBRE INVESTIGACIÓN EN DIDÁCTICA DE LAS CIENCIAS, 9., 2013, Girona. Actas [...]. Girona: [s.n.], 2013. p. 459-462. Disponível em: https://tinyurl.com/y9qrc4ms. Acesso em: 8 jun. 2020.

FERREIRA, D. T. Temas socioambientais: contribuições para o ensino de ciências naturais. 2011. $138 \mathrm{f}$. Dissertação (Mestrado em Educação em Ciências) - Universidade Federal do Pará, Belém, 2011.

FRIDAY FOR FUTURE. Now future generation strike global for climate. 2019. Disponível em: https:// www.fridaysforfuture.org. Acesso em: 2 abr. 2019.

GADOTTI, M. Economia solidária como práxis pedagógica. São Paulo: Instituto Paulo Freire, 2009.

GADOTTI, M. Educar para a sustentabilidade: uma contribuição à década da educação para o desenvolvimento sustentável. São Paulo: Instituto Paulo Freire, 2008.

GOUW, A. M. S. As opiniões, interesses e atitudes dos jovens brasileiros frente à ciência: uma avaliação em âmbito nacional. 2013. 242 f. Tese (Doutorado em educação) - Faculdade de Educação, Universidade de São Paulo, São Paulo, 2013.

INSTITUTO AKATU. Os jovens e o consumo sustentável: construindo o próprio futuro? São Paulo, Brasil, 2003. Disponível em: https://tinyurl.com/y95vvfgl. Acesso em: 8 jun. 2020.

JACOBI, P. R. Educação ambiental: o desafio da construção de um pensamento crítico, complexo e reflexivo. Educação e Pesquisa, São Paulo, v. 31, n. 2, p. 233-250, 2005.

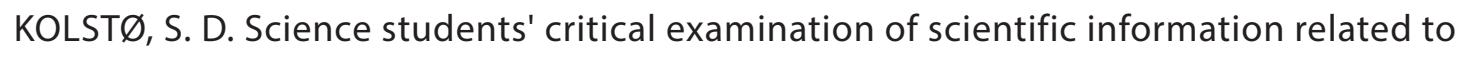
socioscientific issues. Science Education, New York, v. 90, n. 2000, p. 632-655, 2006.

KRASILCHIK, M. Caminhos do ensino de ciências no Brasil. Em Aberto, Brasília, v. 11, n. 55, p. 1-6, 1993.

MALAGODI, M. A. S. Sobre conflitos ambientais e educação ambiental. Pesquisa em Educação Ambiental, Ribeirão Preto, v. 8, n. 2, p. 31-44, 2013.

PINAFO, J. O que os jovens têm a dizer sobre ciência e tecnologia?: opiniões, interesses e atitudes de estudantes em dois países: Brasil e Itália. 2016. Tese (Doutorado em Educação) - Universidade de São Paulo, São Paulo, 2016.

RIBEIRO, T. V.; GENOVESE, L. G. R. O emergir da perspectiva de ensino por pesquisa de núcleos integrados no contexto da implementação de uma proposta CTSA no ensino médio. Ciência \& Educação, Bauru, v. 21, n. 1, p. 1-29, 2015. DOI: https://doi.org/10.1590/1516-731320150010002

RICARDO, E. C. Educação CTSA: obstáculos e possibilidades para sua implementação no contexto escolar. Ciência \& Ensino, Campinas, v. 1, n. esp., p. 1-12, 2008. 
SANTOS, L. R. O.; COSTA, J. J. Educação ambiental e as ciências da natureza: desafios curriculares frente ao exame nacional do ensino médio. In: ENCONTRO INTERNACIONAL DE FORMAÇÃO DE PROFESSORES, 10., 2017, Aracaju. Anais [...]. Disponível em: https://eventos.set.edu.br/index.php/ enfope/article/view/4599/1559. Acesso em 8 jun. 2020.

SANTOS, W. L. P.; MORTIMER, E. F. Abordagem de aspectos sociocientíficos em aulas de ciências: possibilidades e limitações. Investigações em Ensino de Ciências, Porto Alegre, v. 14, n. 2, p. 191-218, 2009.

SILVA, C. S. DE S. Os jovens, as ciências e os desafios ambientais: opiniões, interesses e atitudes dos estudantes do ensino médio do município de Canoas/RS. 2019. 206 f. Tese (Doutorado em Ensino de Ciências e Matemática) - Universidade Luterana do Brasil, Canoas, 2019.

SJØBERG, S.; SCHREINER, C. The ROSE project: an overview and key findings. Oslo: University of Oslo, 2010. Disponível em: https://tinyurl.com/y9w6e2bm. Acesso em: 8 jun. 2020.

TORRES MERCHÁN, N. Y. Enfoque CTSA desde una perspectiva freireana: contribuciones a una educación para el desenvolvimiento sustentable. Educación y Ciencia, Tunja, n. 14, p. 181-192, 2011.

UTPADEL, S. C. A percepção do comportamento consumista em adolescentes de diferentes níveis socioeconômicos. 2007. Trabalho de conclusão de curso (Bacharelado em Psicologia) - Universidade do Vale do Itajaí, Itajaí, 2007.

VILCHES, A.; GIL-PÉREZ, D.; PRAIA, J. CTS a CTSA: educação por um futuro sustentável. In: SANTOS, W. L. P.; AULER, D. (ed.). CTS e educação científica: desafios, tendências e resultados de pesquisa. Brasília: Ed. UnB, 2011. p. 161-184.

WALS, A. E. J.; BRODY, M.; DILLON, J.; STEVENSON, R. B. Convergence between science and environmental education. Science, Washington, v. 344, p. 583-584, 2004. 